\title{
RELATOS DE PESQUISAS
ECONOMIA DA INOVAÇÃO NO CONTEXTO DA CIDADE
DIGITAL ESTRATÉGICA:
CASO DO MUNICÍPIO DE CURITIBA
}

\author{
Djalma de Sá \\ Doutorando em Gestão Urbana pela Pontifícia Universidade Católica \\ do Paraná, Brasil. \\ E-mail: djalmadesa@gmail.com
}

Denis Alcides Rezende

Doutor em Engenharia de Produção pela Universidade Federal de Santa Catarina, Brasil. Professor da Pontifícia Universidade Católica do Paraná, Brasil.

E-mail: denis.rezende@pucpr.br

\begin{abstract}
Resumo
O objetivo deste artigo é compreender como a adoção de um modelo de cidade digital estratégica pode contribuir para o desenvolvimento da economia da inovação baseada no conhecimento no contexto urbano. A fundamentação teórica explora os conceitos de Gestão e Planejamento Municipal, Economia da Inovação, Cidade Inteligente e Cidade Digital. A pesquisa foi dividida em três fases distintas: preparação da pesquisa, a coleta de dados e análise dos dados coletados, com base na análise de um estudo de caso no município de Curitiba. A existência de estratégias municipais, informações e serviços públicos eletrônicos para os cidadãos caracterizam Curitiba como uma cidade digital estratégica. Os resultados demonstram que em Curitiba, o conceito de cidade digital tem como premissa estabelecer condições para o desenvolvimento de atividades econômicas voltadas à tecnologia da informação, gerando uma infraestrutura necessária para o atendimento dos requisitos para o incentivo da economia da inovação baseada no conhecimento. A conclusão, no entanto, demonstra que além da infraestrutura necessária, também é fundamental um planejamento estratégico municipal que oriente a implantação dos ecossistemas de inovação como forma de alavancar a economia urbana baseada no conhecimento.
\end{abstract}

Palavras-chave: Economia da Inovação. Cidade Digital Estratégica. Ecossistemas de Inovação. Economia do Conhecimento

\section{ECONOMY OF INNOVATION IN THE CONTEXT OF THE STRATEGIC DIGITAL CITY: CASE OF THE MUNICIPALITY OF CURITIBA}

\begin{abstract}
The purpose of this article is to understand how the adoption of a strategic digital city model can contribute to the development of the economy of knowledge based innovation in the urban context. The theoretical basis explores the concepts of Municipal Management and Planning, Innovation Economy, Intelligent City and Digital City. The research was divided into three distinct phases: preparation of the research, data collection and analysis of the data collected, based on the analysis of a case study in the city of Curitiba. The existence of municipal strategies, information and electronic public services for citizens characterize Curitiba as a strategic digital city. The results demonstrate that in Curitiba, the concept of digital city has as premise to establish conditions for the development of economic activities focused on information technology, generating an infrastructure necessary to meet the requirements to stimulate the economy of knowledge based innovation. The conclusion, however, shows that beyond the necessary infrastructure, municipal strategic planning is also essential to guide the implementation of innovation ecosystems as a way to leverage the knowledge-based urban economy.
\end{abstract}

Keywords: Innovation Economics. Strategic Digital City. Ecosystems of Innovation. Knowledge Economy.

Perspectivas em Gestão \& Conhecimento, João Pessoa, v. 9, n. 1, p. 62-81, jan./abr. 2019. DOI: http://dx.doi.org/10.21714/2236-417X2019v9n1p62

http://periodicos.ufpb.br/ojs2/index.php/pgc. ISSN: 2236-417X. Publicação sob Licença (cc) EY-NC-ND 


\section{INTRODUÇÃO}

A Constituição Federal de 1988 estabelece que compete aos municípios o ordenamento territorial, utilizando instrumentos de planejamento bem como o controle do uso e a ocupação do solo. O Estatuto das Cidades, por sua vez, define ainda como responsabilidade dos municípios os planos de desenvolvimento econômico e social, como instrumento resultante do planejamento municipal. Desta forma, os municípios têm a responsabilidade de ordenar o território, integrando as funções urbanas, sociais e econômicas, contemplando o atendimento das demandas sociais, a organização da expansão urbana e o desenvolvimento econômico (BRASIL, 2001).

O desenvolvimento econômico do município está ligado às vocações regionais, podendo também ser desenvolvido a partir da capacitação e da readequação do município e do espaço urbano às novas dinâmicas produtivas. Desta forma, podem-se desenvolver novas capacidades econômicas ligadas à indústria, serviços e lazer. A evolução da atividade econômica permitiu o desenvolvimento de um novo modelo de economia baseada em alta tecnologia, produtos e serviços digitais: a economia da inovação tecnológica. Esta nova dinâmica permitiu o desenvolvimento de novas estruturações econômicas nos municípios que se especializaram neste novo modelo, gerando os parques tecnológicos e os ecossistemas de inovação. O poder local é responsável pelo planejamento, implementação e controle de investimentos e projetos de infraestrutura, buscando articular inovação e conhecimento para fomentar o desenvolvimento econômico (FEITOSA, 2011).

A criação de cenários econômicos no município parte da adoção de modelos de desenvolvimento que estabelecem que a decisão sobre a localização das empresas no espaço urbano passa pela definição de alguns critérios como contingente de mão de obra, infraestrutura logística, instituições de formação e capacitação de mão-de-obra. Municípios com centros industriais estabelecidos atraem mão-de-obra especializada, instituições de ensino e pesquisa para ampliar a capacidade de inovação, investem em infraestrutura logística de escoamento além de estar geograficamente localizado próximo a portos, aeroportos e mercados consumidores. Alguns destes fatores, como mão de obra capacitada e a existência de instituições de ensino, também são formas de atração para a economia da inovação. No entanto, como não dependem diretamente da escoação de produtos, a nova economia depende da infraestrutura tecnológica, de tráfego e armazenamento de dados, estrutura necessária para a geração de soluções tecnológicas e atividades de pesquisa e desenvolvimento, incluindo compra de patentes, licenças ou sistemas informatizados (MUSOLESI; HUIBAN, 2010).

Desta forma, as políticas públicas precisam fomentar o desenvolvimento de uma infraestrutura que se adeque ao modelo econômico adotado, articulando a agenda governamental à evolução dos processos produtivos. O desenvolvimento econômico deve ser entendido como um processo de transformações econômicas, políticas e, principalmente, sociais. Neste sentido, a adequação da cidade a novos modelos produtivos garante a sustentabilidade econômica e a capacidade de produção contínua. As políticas de desenvolvimento econômico local interagem com o território, estabelecendo novas características competitivas e determinando novas dinâmicas produtivas no município (STRACHULSKI, 2017).

A partir dos anos 1990, com o processo de abertura política e a consequente abertura dos mercados, ocorre um avanço do processo de globalização em direção aos mercados emergentes. A consequência deste processo no âmbito municipal foi a readequação do papel dos municípios e a reorganização da economia urbana, desenvolvendo fatores de atratividade para a instalação de empresas multinacionais. O processo de globalização também é

Perspectivas em Gestão \& Conhecimento, João Pessoa, v. 9, n. 1, p. 62-81, jan./abr. 2019. 
importante para definir um novo modelo de sociedade: a sociedade do conhecimento (Castells vai denominar sociedade informacional) que, com o advento das tecnologias de informação, amplia as possibilidades de transmissão e troca de conhecimento (CASTELLS, 2010).

Castells (2010) define um novo modelo de economia (denominada Economia Informacional) que se distingue do conceito de Sociedade Informacional, pois, ao contrário desta que trata da transmissão do conhecimento, aquela trata da produção de conhecimento na produção de novos produtos ou serviços. Essa nova economia desenvolve novas possibilidades produtivas como Ecossistemas de Inovação, Startups, Indústria 4.0, economia criativa, economia do conhecimento, clusters, entre outros.

A partir desta nova organização global da economia, os municípios buscam implantar ou ampliar a infraestrutura tecnológica, construindo novos modelos de desenvolvimento urbano que possibilitem conectar os serviços públicos, empresas, organizações de terceiro setor e sociedade, procurando ser estabelecidas dentro do conceito de cidade digital. A partir dessa premissa, esse artigo parte da definição do seguinte problema: Como a adoção de um modelo de cidade digital estratégica pode contribuir para o desenvolvimento da economia da inovação no contexto urbano?

O objetivo deste artigo é compreender a relação entre a existência de uma cidade digital estratégica e a sua contribuição para o desenvolvimento da economia da inovação baseada no conhecimento, necessários para adequar-se a nova dinâmica produtiva global.

Os problemas de pesquisa relacionados a cidade digital estratégica estão principalmente relacionados com a falta de estratégias, de informações e de serviços públicos por meio dos recursos da tecnologia da informação em cidades. E por sua vez, as justificativas de pesquisa reiteram a necessidade do planejamento e gestão de estratégicas em cidades, embasadas em informações municipais e serviços públicos eletrônicos oferecidos aos cidadãos (REZENDE, 2012; REZENDE, 2018).

O tema é relevante por discutir a vinculação do desenvolvimento econômico ao planejamento estratégico municipal suportado no conceito de cidade digital estratégica como forma de promover a cultura da inovação, da competitividade, do aumento da capacitação empresarial, fundamentado na transferência de conhecimento e tecnologia, com o objetivo de incrementar a produção de riqueza de uma região (GIUGLIANI; SANTOS; SELIG, 2012).

Cabe destacar ainda que, como este novo modelo de economia está fortemente ligado à produção de ativos baseados no conhecimento, ancorados em tecnologias de comunicação, a existência de uma infraestrutura lógica para distribuição e armazenamento de dados contribui para a construção de um cenário propicio à inovação. Neste tocante, faz-se sentido discutir as possibilidades de adequação desta nova economia num contexto de cidade digital quem, por sua vez apresenta fortes conexões com as tecnologias de informação.

\section{FUNDAMENTAÇÃO TEÓRICA}

\subsection{Gestão municipal e planejamento municipal}

A gestão municipal contempla a administração dos recursos da cidade com o objetivo de atender o interesse público coletivo, sua diversidade, contratos e interesses por meio do estabelecimento de políticas públicas no contexto do município, devendo estar de acordo com os princípios básicos da administração pública e garantindo a participação dos cidadãos no processo. Nas últimas décadas, a formulação e a execução das políticas públicas tem passado cada vez mais pelas capacidades do poder local e pelas ações da gestão municipal (VELOSO et al., 2011).

Para que a efetividade das políticas públicas na gestão municipal, a gestão urbana, entendida como a gestão da cidade, utilizar-se-á de instrumentos de planejamento municipal

Perspectivas em Gestão \& Conhecimento, João Pessoa, v. 9, n. 1, p. 62-81, jan./abr. 2019. 
para a definição clara de objetivos a serem alcançados, tendo caráter obrigatório e são normatizadas por um ordenamento jurídico. A gestão municipal está relacionada com o conjunto de instrumentos e os diversos recursos disponíveis (REZENDE; CASTOR, 2006).

O plano plurianual (PPA) é um instrumento exigido pela constituição federal de 1988 em seu artigo 165, que se estende do segundo ano de um mandado do prefeito municipal até o primeiro ano do mandato subsequente. O PPA estabelece os objetivos, estratégias e ações para as despesas de capital e outras dela decorrentes, definindo a política de investimentos do município nos quatro anos de duração do plano (CIDADES, 2005).

A partir do PPA tem-se a derivação para a Lei de Diretrizes Orçamentárias (LDO), de periodicidade anual definindo as metas e prioridades da administração pública para as despesas de capital e que são inseridas na Lei Orçamentária Anual (LOA). A LOA também é de periodicidade anual e estabelece a política fiscal de receitas e despesas correntes e de capital do município, constituída dos orçamentos fiscal, de seguridade social e de investimento das estatais (BRASIL, 1988).

O Estatuto das Cidades estabelece que os municípios precisam elaborar seus planos diretores como forma de regulamentar o desenvolvimento urbano, espacial e econômico. 0 plano diretor municipal é um plano de organização e planejamento físico-territorial do município, sendo obrigatório para municípios com mais de 20 mil habitantes, integrantes de regiões metropolitanas e aglomerações urbanas, com áreas de especial interesse turístico, situados em áreas de influência de empreendimentos ou atividades com significativo impacto ambiental na região ou no país (CIDADES, 2004).

Em 1995 tem inicio o processo de reforma administrativa do Estado, adotando alguns conceitos da Administração Pública Gerencial (New Public Management), destacando a descentralização decisória e das funções do estado, que passa a atuar com foco nos resultados apresentados, busca de uma maior eficiência do serviço público e profissionalização do funcionário público, transparência nas decisões administrativas, maior eficiência financeira baseada em formas de controle de resultados, avaliação de desempenho, e gestão participativa. A Reforma Bresser preconizava a divisão do Estado em quatro setores: núcleo estratégico, atividades exclusivas, serviços não exclusivos e produção de bens e serviços para o mercado (FERNANDES; MORAES; NASCIMENTO, 2015).

Em 2000 é instituída a Lei de Responsabilidade Fiscal (LRF) como forma de criar normas para a responsabilização dos agentes quanto aos gastos públicos do Estado. Em conjunto com a reforma administrativa do Estado, a LRF reforça a necessidade de considerar o planejamento como a ferramenta mais importante para a eficácia da gestão municipal. Devido às novas necessidades e o novo papel do Estado na visão da Nova Gestão Pública, cabe aos gestores municipais estabelecer objetivos de longo prazo para a determinação dos objetivos, estratégias e ações do município e da prefeitura, estruturada nas seguintes recomendações: ação planejada e transparente; prevenção de riscos; equilíbrio das contas públicas; cumprimento de metas e de resultados; e cumprimento de vários limites (GERIGK et al., 2011).

O Planejamento Estratégico Municipal coordena os vários níveis e funções estratégicas de uma cidade em um projeto global, considerando a missão, as estratégias, o orçamento e o controle dos objetivos e das ações municipais. O planejamento permite que a capacidade de resposta da gestão municipal seja articulada com as demandas e necessidades da sociedade, definindo novos focos e objetivos municipais, que vão formar uma nova expectativa de atuação política futura. Rezende (2009) destaca fatores que contribuem para o sucesso do planejamento municipal, como a divulgação, capacitação os elaboradores do projeto, alinhado com a realidade e com o orçamento do município e fatores particulares da região. 


\subsection{Economia da inovação e o papel do Estado}

A inovação é essencial para a concorrência em mercados desenvolvidos e organizados, sendo essencial para as empresas como modelo de competitividade. Desta forma, a inovação leva à alteração dos processos da base produtiva industrial contribuído para o crescimento da empresa e o desenvolvimento econômico de longo prazo. Essa abordagem tem como fundamentação a Teoria das Inovações Induzidas (TII) que tem origem nos trabalhos de Hayami e Ruttan que destacava o papel do setor público na geração da inovação a partir das mudanças institucionais implementadas pelo Estado. A Teoria das Inovações Induzidas (TII) de Hayami e Ruttan destaca quatro características distintas: inovação induzida pelo Estado, inovação induzida pelo setor privado, interação entre mudança técnica e desenvolvimento institucional, sequência dinâmica de mudança técnica e crescimento econômico.

Segundo dados da Pesquisa de Inovação Tecnológica na Industria (PINTEC) e do Instituto Brasileiro de Geografia e Estatística (IBGE), há diferenças significativas entre as empresas que inovam e as que não que não fazem. $O$ estudo também destaca a necessidade de políticas públicas para fomentar e incentivar modelos de inovação. As empresas que adotam políticas de inovação apresentam aumento de faturamento, de produtividade e de emprego de mão de obra. A inovação também aumenta a competitividade das empresas no mercado internacional e as condições de exportação. Em relação ao mercado de trabalho, empresas inovadoras pagam salários maiores, contratam profissionais com maior escolaridade e apresentam maior estabilidade de emprego (IBGE, 2014).

Cano e Silva (2010) destacam que as políticas industriais são fundamentais para estimular os modelos de inovação, baseado em dois conceitos tradicionais distintos: o primeiro é mais amplo e objetiva uma ação mais horizontal, garantindo condições do ambiente econômico, priorizando investimento em infraestrutura e educação e políticas macroeconômicas e de regulação. O segundo conceito trata de uma atuação de governo mais direcionada, por meio de intervenções diretas mais específicas com políticas mais verticais.

Para realizar o processo de indução da economia da inovação, o Estado promove sistemas locais de inovação, contemplando um marco legal, espaços para participação da sociedade civil organizada, estrutura hierárquica e pessoal especializado, fontes de financiamento e políticas de fomento, além de outras formas de incentivo por meio de isenções e outras formas de parceria com o setor privado. O Estado também contribui com a oferta, organização e desenvolvimento da infraestrutura de redes e telecomunicações necessárias para o atendimento desta nova economia.

A Constituição Federal de 1988 tornou-se um marco importante na mudança da estrutura federativa do Estado, estabelecendo a autonomia dos municípios e permitindo a estes a aplicação de políticas locais de desenvolvimento, contemplando as especificidades econômicas, ambientais e sociais próprias. Desta forma, a descentralização das políticas públicas permitiu a união do ordenamento territorial com novas dinâmicas econômicas. Tendo em conta o papel histórico desenvolvido pelos municípios brasileiros, as instituições políticas, econômica, culturais, educacionais, entre outras, representam um viés para mudanças qualitativas em muitos governos locais. Desta forma, a Constituição Federal estabelece os dois principais eixos para organização das políticas públicas: a descentralização e a participação popular (FREITAS, 2015).

O desenvolvimento econômico é o resultado de um processo que altera fatores econômicos, políticos, humanos e sociais não podendo ser entendido como o avanço dos indicadores de renda e elevação do Produto Interno Bruto. Desta forma, o desenvolvimento econômico permite de mudança qualitativa na estrutura econômica e social, descrevendo os fatores fundamentais para um processo de desenvolvimento econômico, como sendo: inserir todos os segmentos sociais a novas dinâmicas econômicas e políticas-culturais; gerar e

Perspectivas em Gestão \& Conhecimento, João Pessoa, v. 9, n. 1, p. 62-81, jan./abr. 2019. 
consolidar as iniciativas empreendedoras locais; harmonizar e regular as relações comunidade e empresa em seu contexto sócio ambiental; construir a sustentabilidade econômica das atividades locais; e desenvolver ambiente inovador e gerador de oportunidades. O poder local precisa organizar o planejamento do desenvolvimento econômico associado à atuação do setor privado (VIEIRA; SANTOS, 2012).

Schumpeter (1988) enfatiza que o desenvolvimento é consequência de alterações do cenário econômico, definindo pré-requisitos para novos processos de desenvolvimento, criando uma ruptura no modelo econômico. Para Schumpeter, o pilar do desenvolvimento econômico é a atração de grandes empresas para a região, que permite a concentração de conhecimentos e de criatividade e eleva a capacidade de inovação da região por meio do diferencial competitivo.

No tocante à inovação, pode-se observar no Brasil a adoção de políticas públicas que buscam incentivar, estruturar e organizar ambientes de inovação que permitam a participação e interação dos setores públicos e privado e possibilitando a prática do trinômio: ciência, tecnologia e inovação. Neste contexto, os municípios permitem o desenvolvimento de habitas de inovação, interagindo com os diversos atores sociais envolvidos: instituições de ensino e pesquisa, o setor empresarial, entidades representativas de classe, além de fatores atrativos da economia urbana local como a infraestrutura urbana adequada, meios de comunicação e mão-de-obra qualificada, aproximando os atores para a implantação das políticas de pesquisa e desenvolvimento tecnológico (QUADROS, 2010).

O debate sobre inovação tem ganhado espaço nas políticas de desenvolvimento econômico municipal definindo um caráter local para a inovação, estabelecendo as relações econômicas entre o global e o local, definindo um novo papel econômico e político para os planejadores municipais. Nesta perspectiva, o desenvolvimento de parques tecnológicos como fator de atração econômica surge como uma possibilidade de implantar novas práticas para dinamizar o desenvolvimento econômico (GIUGLIANI; SANTOS; SELIG, 2012).

A ideia da inovação vem sendo mal compreendida e caracterizada, confundindo os conceitos de inovação e difusão. O processo de inovação é um fenômeno típico dos países desenvolvidos, ancorados em tecnologia, produção e difusão do conhecimento. Nos países em desenvolvimento, os processos de inovação são adotados por meio da difusão tecnológica dos países desenvolvidos por meio de formas diversas: inovação aberta ou inovação soft (STONEMAN, 2010). Schumpeter (1982, p. 48 e 49) apresenta cinco formas de inovação: 1) desenvolvimento de um novo produto; 2 ) introdução de um novo método de produção; 3 ) abertura de um novo mercado; 4) descoberta ou conquista de uma nova fonte de matérias primas ou produtos semiacabados e 5) criação de uma nova indústria ou monopólio.

Para autores como Chesbrough (2012) a ideia da inovação tem uma forte relação com a interação das empresas com os demais atores, onde ocorre a partilha de ideias e conhecimentos entre as partes interessadas e fomenta a cooperação entre os envolvidos, os concorrentes e os participantes do mercado. Esse relacionamento entre as partes forma uma rede de colaboração, tendo como ponto alto a formação de ecossistemas de inovação tecnológica.

Nos anos 1990, Henry Etzkovitz desenvolve o modelo da tríplice hélice envolvendo três atores principais: a universidade, a indústria e o governo, no desenvolvimento de políticas de inovação. $O$ modelo estabelece que a inovação tecnológica ocorre quando o conhecimento desenvolvido nas universidades é direcionado para atender demandas econômicas-sociais que as entidades privadas e empresas analisam, gerenciam e, posteriormente comercializam, com o apoio de políticas públicas que visem coordenar o desenvolvimento do potencial de setores e regiões e gerir os modelos contratuais das parcerias entre os diferentes atores. Esse modelo colabora para a elevação do desenvolvimento econômico e para fomentar as condições de competitividade da região (ETZKOWITZ; LEYDESDORFF, 2000).

Perspectivas em Gestão \& Conhecimento, João Pessoa, v. 9, n. 1, p. 62-81, jan./abr. 2019. 
A partir das interações da tríplice hélice podem-se definir novas formas de organização da economia urbana advindas das articulações entre os atores envolvidos. Desta forma desenvolve-se o conceito de Ecossistemas de Inovação, que podem ser compreendidos como uma rede formada por empresas e outras entidades conectadas, que buscam 0 desenvolvimento de novos produtos ou serviços a partir do compartilhamento de conhecimentos, habilidades e tecnologias de forma cooperada (NAMBISA; BARON, 2013).

\subsection{Sociedade informacional e a economia do conhecimento}

O termo "economia do conhecimento" foi desenvolvido por Drucker (1969) se referindo aos incentivos ao desenvolvimento econômico baseados na aplicação do conhecimento de qualquer campo ou fonte, desenvolvendo novos produtos, processos ou serviços. Assim, compreende-se o determinismo tecnológico sobre a dinâmica social, formando assim a sociedade do conhecimento a partir dos recursos governamentais para incentivo à inovação (GALLON; REINA; ENSSLIN, 2010).

O conhecimento sempre foi fundamental para a dinâmica de funcionamento de qualquer sociedade. $\mathrm{O}$ avanço econômico das sociedades sempre foi marcado pela presença do conhecimento teórico, ganhando um novo papel a partir do determinismo tecnológico "quando o conhecimento se torna envolvido de alguma forma sistemática na transformação aplicada dos recursos, então se pode dizer que o conhecimento, não o trabalho, é a fonte de valor". Assim a "teoria do valor do conhecimento" passou a ser o principal fator da riqueza das sociedades econômicas avançadas, orientando processo de Pesquisa e Desenvolvimento das organizações e o desenvolvimento das políticas públicas para os governos locais, contribuindo para aumentar a competitividade dos municípios (LEONELLI, 2010).

Para Castells (2010) a sociedade do conhecimento desenvolveu uma nova tríade de fatores de produção: geração, processamento e transmissão de informações (em substituição aos fatores clássicos: terra, capital e trabalho). Além disso, Castells destaca que a nova sociedade e economia do conhecimento funcionam numa perspectiva global e organizada em redes de colaboração e desenvolvimento, concentrando-se sob a égide da Tecnologia da Informação e da Comunicação (TIC) e de seu impacto sobre a dinâmica social. Este contexto levou a um novo cenário econômico - uma economia informacional - marcado por produção e demanda de informação crescente. A produção é marcada por um desenvolvimento tecnológico e geração de dados e a demanda, como consequência da geração de informação, leva à ampliação das tecnologias existentes e das TICs, contribuindo para a acumulação da riqueza.

Essa discussão do determinismo tecnológico a partir do advento das tecnologias de informação e comunicação estabeleceu uma nova relação entre a ciência e a sociedade. Alguns fatores contribuíram para a mudança no status da interação entre a tecnologia e a sociedade como o surgimento do conceito da "tríplice hélice", contemplando as relações entre a universidade, indústria e o Estado, ampliando os grupos interessados na produção de conhecimento. Um segundo fator remete à concorrência global, ancorada na capacidade da nova economia de resolver problemas cotidianos ancoradas em instrumentos baseados em conhecimento. Nesse sentido, o Estado tem a responsabilidade de garantir a competitividade da economia no longo prazo permitindo-lhe tratar, de modo adequado, os principais desafios estratégicos do país em qualquer contexto (CALMANOVICI, 2011).

Gibbons et al. (1994) distingue os modos de produção de conhecimento em dois modelos: o primeiro é voltado para a produção acadêmica do conhecimento desenvolvido nas universidades por pesquisadores e professores. Um segundo grupo busca a relação entre a teoria e a prática num contexto de aplicação da tecnologia, a partir da interação entre a universidade e a indústria, a partir da articulação do Estado por meio das políticas públicas

Perspectivas em Gestão \& Conhecimento, João Pessoa, v. 9, n. 1, p. 62-81, jan./abr. 2019. 
estabelecidas. Esse contexto de produção do conhecimento é amplamente desenvolvido em cenários de inovação aberta a partir de espaços organizados, como os ecossistemas de inovação e os parques tecnológicos. Estes espaços tornam-se locais de produção de conhecimento como as incubadoras, investimentos empresariais de pesquisa e desenvolvimento e empresas de capital de risco (ETZKOWITZ, 2009)

\subsection{Cidade digital, cidade inteligente e cidade digital estratégica}

O conceito de cidade digital, embora bastante estudado e amplamente discutido, ainda não apresenta um consenso no meio acadêmico dependendo do grau de desenvolvimento e industrialização da região e das características sociopolíticas locais. 0 conceito é mais abrangente que simplesmente as relações no ciberespaço, contemplando as discussões sobre o planejamento da cidade e a oferta de serviços, aproximando a gestão municipal da sociedade (SIMÃO; SUAIDEN, 2012).

A cidade digital é o ambiente de rede digital criado no território que conecta os serviços públicos, empresas, organizações de terceiro setor e sociedade por meio de sistemas tecnológicos avançados, disponibilizando diversas informações para desenvolver as necessidades da sociedade de informação e colocar o cidadão na condição de protagonista da nova territorialidade virtual organizada no ciberespaço. Assim, as cidades se organizam para que o ambiente virtual amplie as possibilidades de relações sociais entre os habitantes (BESSELAAR; BECKERS, 2009).

O conceito de cidade inteligente, no entanto, é definido pelo World Foundation for Smart Communities (2001) como a associação das cidades digitais ao crescimento feito de forma inteligente, tendo como base as tecnologias de informação, gerando uma transformação significativa e não somente incremental.

Todas as cidades Inteligentes são também cidades digitais, mas nem todas as cidades digitais são inteligentes. A diferença está na aplicabilidade da tecnologia para resolver problemas da cidade, enquanto o foco da cidade digital está na oferta de serviços por meio da utilização da comunicação digital, disponibilizando à sociedade acesso a banda larga de alta velocidade, incentivando a inclusão digital e o desenvolvimento da economia urbana (STRAPAZZON, 2011).

Diferentemente do conceito de cidade digital convencional e de cidade inteligente, a cidade digital estratégica como a aplicação dos recursos de tecnologia da informação na gestão municipal, disponibilizando informações e serviços para os cidadãos e está embasada nos objetivos e nas estratégias da cidade. Para a implantação da cidade digital estratégica é necessário que o município desenvolva previamente um planejamento estratégico municipal, definindo objetivos e estratégias por meio das temáticas municipais. Faz-se necessário ainda a elaboração do planejamento de informações municipais, planejamento da tecnologia da informação (REZENDE, 2012; REZENDE, 2018).

As cidades digitais entendidas como primeira etapa para as cidades inteligentes fazem parte de uma nova forma de distribuição do fluxo de informação da sociedade. A cidade, ao estabelecer regiões dinâmicas de inovação estabelece um território de interação dos setores econômicos com processos e atores envolvidos com as políticas de tecnologia de $\mathrm{Tl}$, definindo um novo processo de desenvolvimento econômico. Nestas regiões de inovação é preciso que os atores envolvidos (em particular a gestão municipal) desenvolvam políticas urbanas, tecnológicas e de conhecimento de forma harmoniosa no estabelecimento de estratégias para o território, utilizando as tecnologias para nortear as decisões do governo, empresas e cidadãos, tornando a cidade um organismo com maior funcionalidade (LEMOS, 2013).

A nova característica da cidade interage com a dinâmica contemporânea a partir da digitalização de diversos elementos do cotidiano urbano como o trabalho on-line, o comércio

Perspectivas em Gestão \& Conhecimento, João Pessoa, v. 9, n. 1, p. 62-81, jan./abr. 2019. 
eletrônico, educação à distância, o acesso aos serviços públicos ou mesmo as formas de diversões em rede. Esses elementos que se caracterizam como fluxos de informação podem ser compreendidos como uma nova dimensão do espaço urbano e fortalecendo a cidade física. Esse espaço de fluxo é uma das características das cidades virtuais, bem como é o espaço das cidades que constituem os grandes polos de desenvolvimento econômico (CASTELLS, 2010).

$\mathrm{O}$ advento do conceito de cidade digital apresenta diversos desafios aos planejadores e gestores municipais para que os benefícios das tecnologias da informação sejam assimilados pelas cidades. Os responsáveis pelo planejamento urbano, neste novo cenário, precisam levar em consideração a influência do ciberespaço na organização do espaço urbano. A cidade digital deve possibilitar uma nova democracia mais próxima da democracia ateniense, possibilitando a reunião de cidadãos que se encontram e discutem juntos em um novo espaço público (LEVY, 2010).

\section{METODOLOGIA DA PESQUISA}

A natureza da pesquisa está voltada para a pesquisa aplicada, uma vez que o resultado desta pesquisa pode ser aplicado de uma forma prática para a compreensão do papel do desenvolvimento da economia da inovação no contexto da cidade digital estratégica.

O artigo apresenta uma abordagem qualitativa porque se utilizou de pesquisas bibliográficas e dados secundários para a discussão proposta, apresentando os dados quantitativos como instrumento auxiliar de análise. Apresenta ainda um perfil descritivo estabelecendo a partir das características de determinado fenômeno, relações entre variáveis distintas (GIL, 2008).

Para estudo dos processos e das variáveis apresentadas utilizou-se a pesquisa bibliográfica e documental buscando obter de fontes já elaboradas base para a descrição do tema pesquisado. Em relação aos procedimentos, será utilizado o estudo de caso pois busca conhecer em profundidade o como e o porquê de uma determinada situação, procurando descobrir o que há nela de mais essencial e característico (FONSECA; 2002).

Para a realização do objetivo proposto, a pesquisa foi dividida em três fases distintas: preparação da pesquisa, a coleta de dados e análise dos dados coletados. A preparação da pesquisa incluiu a revisão da literatura constante na fundamentação teórica. A coleta de dados se dá por meio de levantamento de dados junto ao plano plurianual e a demais documentos do município. Para análise dos dados coletados no levantamento utilizou-se a abordagem qualitativa de acordo com os constructos e variáveis definidas.

Apresenta-se ainda o protocolo de pesquisa para definição de controle e forma de mensuração das variáveis. Para o atingimento deste objetivo, foram selecionados dois construtos: Economia da Inovação e Cidade Digital Estratégica. Os construtos selecionados estão diretamente ligados ao tema do artigo e à fundamentação teórica e foram analisados no período de fevereiro a novembro de 2017 (período de discussão e aprovação do plano plurianual do município).

O primeiro constructo trata do tema "Economia da Inovação", abordando como primeira macro variável o Plano Plurianual do Município e procura medir a existência de investimentos no desenvolvimento em Inovação no PPA municipal no período 2018-2021. Para alcançar este objetivo, buscou-se informações do Plano de Governo e o orçamento correspondente no Plano Plurianual do município. A segunda macro variável deste constructo trata do "Novo Modelo Econômico" e busca compreender a evolução da economia da inovação no município de Curitiba por meio das políticas públicas voltadas para o fomento da economia da inovação. O segundo constructo refere-se ao tema "Cidade Digital Estratégica", apresentando o tema Planejamento Estratégico Municipal como terceira macro variável buscando medir a existência de um Planejamento Estratégico Municipal no município de

Perspectivas em Gestão \& Conhecimento, João Pessoa, v. 9, n. 1, p. 62-81, jan./abr. 2019. 
Curitiba. A quarta macro variável refere-se ao tema "Cidade Digital" e busca medir a existência de um projeto de Cidade Digital no município de Curitiba. Para compreender este constructo e o atendimento das macro variáveis buscou-se a identificação das diretrizes de inovação no Planejamento Estratégico do município e compreender a infraestrutura de telecomunicações e redes disponibilizada para atingir este planejamento.

\section{ANÁLISE DAS RELAÇÕES DA ECONOMIA DA INOVAÇÃO COM A CIDADE DIGITAL ESTRATÉGICA}

\subsection{Análise da política de incentivo à economia da inovação no plano plurianual de Curitiba} (2018-2021)

O Plano Plurianual (PPA) para o período de 2018-2021 estabelece a Economia da Inovação como o modelo propulsor para o desenvolvimento econômico municipal. O plano de desenvolvimento está ancorado no Ecossistema de inovação do "Vale do Pinhão" e descreve um eixo de sustentabilidade que busca a promoção de soluções inovadoras a partir da tecnologia, destacando Curitiba como uma cidade inteligente e atrativa para negócios inovadores. O plano conta com o apoio de instituições locais como o Serviço de Apoio às Micro e Pequenas Empresas do Paraná (SEBRAE-PR), a Federação das Indústrias do Estado do Paraná (FIEP) e a Federação do Comércio de Bens, Serviços e Turismo do Paraná (FECOMERCIO-PR).

$O$ ecossistema também está ancorado em quatro grandes universidades existentes na cidade, a Pontifícia Universidade Católica do Paraná (PUC-PR), a Universidade Tecnológica Federal do Paraná (UTFPR), a Universidade Positivo (UP) e a Universidade Federal do Paraná (UFPR). Essa interação de instituições representativas e de universidades alinhadas ao plano municipal de Inovação, baseada no conceito de tríplice hélice, busca desenvolver ações em três pilares fundamentais: Inovação na Prefeitura, Internacionalização e Crescimento do Ecossistema. Para fomentar este ecossistema, em 2007, desenvolve-se a Lei Municipal de Inovação e o Conselho Municipal de Inovação como forma de dar sustentabilidade legal e política ao Ecossistema de Inovação.

O plano estabelece que 20 startups serão aceleradas até 2020 e define legislação e incentivos municipais para a inovação, a partir da criação do Conselho Municipal de Inovação, da Lei da Inovação e das Startups, da nova Lei do ISS Tecnológico, do Tecnoparque e do Parque de Software, bem como busca desenvolver um Fundo Municipal para a Inovação. Além dessas ações, nas administrações regionais estuda-se a instalação de coworkings e fab labs para desenvolvimento de novos projetos de negócios.

\subsection{Análise do desenvolvimento da economia da inovação no município de Curitiba}

A estrutura econômica das cidades passa pelo estabelecimento de políticas públicas, pela definição de incentivos fiscais, pelo ordenamento do território para receber a nova atividade e pela implantação de infraestrutura necessária para atender a nova atividade.

No tocante às políticas públicas, o programa Curitiba Tecnoparque com os objetivos de fomentar o desenvolvimento de empresas de base tecnológica e instituições de ciência e tecnologia, e de difundir a cultura de conhecimento e inovação de setores estratégicos de alta tecnologia no Município de Curitiba. Os setores de atividades incentivadas pelo programa são: Sistemas de Telecomunicações: equipamentos e serviços; Equipamentos de Informática: hardware e periféricos; Serviços de Informática: desenvolvimento de software, consultoria em hardware e software, gestão de dados e distribuição eletrônica de informações; Pesquisa e Desenvolvimento; Design; Laboratórios de Ensaios e Testes de Qualidade; Instrumentos de

Perspectivas em Gestão \& Conhecimento, João Pessoa, v. 9, n. 1, p. 62-81, jan./abr. 2019. 
Precisão e Automação Industrial; Novas Tecnologias: Biotecnologia, Nanotecnologia, Saúde, Novos Materiais e Tecnologias Ambientais.

O programa apresenta uma abrangência definida em áreas delimitadas, sendo:

- O Anel Logístico, contendo o Núcleo Empresarial, onde estão localizadas a Pontifícia Universidade Católica do Paraná, o Instituto de Tecnologia para o Desenvolvimento (LACTEC), Federação das Indústrias do Paraná, Universidade Federal do Paraná e o eixo estrutural da av. Marechal Floriano Peixoto e Linha Verde;

- O Anel CIC Norte, contendo o Parque de Software, fundado em 1996 em conjunto com a iniciativa privada local, com objetivo de transformar a cidade num importante centro de excelência em tecnologia de software, de nível internacional;

- O Setor Central Rebouças, contendo a Universidade Tecnológica Federal do Paraná e o Centro de Convenções;

- Setor CIC Sul, contendo o Instituto de Tecnologia do Paraná.

Para o programa Curitiba Tecnoparque, a prefeitura estabelece a alíquota de $2 \%$ de Imposto sobre Serviço - ISS de uma forma geral. Para as empresas que se instalarem no Núcleo Empresarial, o regime de tributação imobiliária dessas empresas será de: Isenção do Imposto Sobre a Transmissão "inter vivos" de Bens Imóveis - ITBI referente à aquisição de imóvel destinado à sua implantação ou ampliação de atividades Isenção, pelo prazo de dez anos, do Imposto sobre a Propriedade Predial e Territorial Urbana e das taxas de serviços e pelo poder de polícia e contribuição de melhoria.

Para as empresas que se instalarem no Parque de Software, o município apresenta os seguintes incentivos: alíquota de $2 \%$ do Imposto Sobre Serviços - ISS; Isenção do imposto sobre Transmissões de Bens Imóveis - ITBI por ato "inter vivos" quando da aquisição de terreno localizado no Setor Especial do Parque de Software destinado à implantação da empresa ou ampliação de sua área física; isenção do Imposto Predial e Territorial Urbano - IPTU, por dez anos; isenção de Taxas pelo exercício do poder de polícia, por dez anos; isenção Contribuição de Melhoria, por dez anos.

Em 2012, a Prefeitura municipal estendeu o benefício para toda a cidade, ampliando os limites geográficos para além das quatro 4 áreas anteriormente definidas por lei. Em 2017, a prefeitura municipal estabelece o Ecossistema de Inovação denominado "Vale do Pinhão", voltado para ações de ocupação e reurbanização do bairro do Rebouças.

No ano de 2017, a Prefeitura municipal instituiu e regulamentou o Engenho da Inovação que tem como objetivo fomentar o ambiente para o desenvolvimento do ecossistema de inovação promovendo eventos voltados para a realização de negócios, disseminando tecnologias, capacitando empreendedores e disponibilizando espaço de trabalho compartilhado, observados os requisitos legais. O espaço é destinado para eventos culturais e empresariais voltados à inovação, concentrando espaço de escritório compartilhado e uma incubadora para o desenvolvimento de novas tecnologias. A prefeitura tem a intenção de, num segundo momento, instalar centros de pesquisas e desenvolvimento de grandes empresas no local.

A partir do Engenho de Inovação desenvolveu-se o projeto do Vale do Pinhão (referência ao Vale do Silício) que tem por objetivo inicial atrair empresas para a região do bairro do Rebouças. $O$ foco do projeto são as startups a partir da concessão de incentivos territoriais e fiscais para a atração e concentração de pesquisadores, empreendedores e empresas com foco em desenvolver soluções inovadoras. O projeto busca a interligação de diversas instituições que incentivem a inovação como Sebrae, Federação das Indústrias, Federação do Comércio e Associação Comercial do estado. Também busca usar a estrutura das Salas do Empreendedor localizadas nas das Ruas da Cidadania (braço descentralizado da

Perspectivas em Gestão \& Conhecimento, João Pessoa, v. 9, n. 1, p. 62-81, jan./abr. 2019. 
prefeitura) para qualificar os novos empresários em inovação, construindo uma cultura empresarial inovadora.

Para induzir o desenvolvimento tecnológico e a economia de inovação no município de Curitiba foi implantada, no ano de 2018, a lei municipal de Inovação. Esta lei prevê 12 formas distintas de fomento às empresas de base tecnológica e a outros negócios de cunho tecnológico, contemplando inclusive a possibilidade de a prefeitura ser sócia minoritária. A proposta cria a figura legal das instituições científicas, tecnológicas e de inovação (ICTs), a serem certificadas pelo Executivo, que poderão se organizar em incubadoras, polos e parques tecnológicos. A lei autoriza a prefeitura a ceder imóveis e a participar da criação e da governança de incubadoras e parques tecnológicos. A lei ainda estabelece subvenção econômica, financiamento, participação societária, bônus tecnológico, encomenda tecnológica, incentivos fiscais, concessão de bolsas, compra direta, fundos de investimento, fundos de participação, títulos financeiros e possibilidade revisão de investimento em pesquisa e desenvolvimento em contratos de concessão de serviços públicos ou em regulações setoriais. A lei municipal prevê a criação do Fundo Municipal de Inovação a fim gerar financiamentos e dos instrumentos de construção do ecossistema de inovação na cidade.

Para garantir a participação da sociedade civil na construção de políticas públicas de inovação foi instituído, no ano de 2018, o Conselho Municipal de Inovação, formado por representantes do poder público municipal, instituições de ensino superior e setor produtivo. Dos 12 membros previstos, quatro serão indicados pelo município (três indicados pela prefeitura e um vereador), quatro virão do setor econômico (indicados pela ACP, Fecomércio, Fiep e Sebrae-PR) e quatro representantes do ensino superior (UFPR, UTFPR, PUCPR e UP). O papel do conselho é formular e propor diretrizes e ações para promoção da ciência, tecnologia e inovação, fazer estudos e acompanhar a implementação das políticas no setor. O critério estabelecido para a participação no Conselho é a competência técnica nas áreas de ciência, tecnologia, inovação e desenvolvimento econômico, podendo contar com assessores ou comissões técnicas, desde que respeitadas as mesmas exigências.

\subsection{Análise do Planejamento do município de Curitiba}

O conceito de planejamento estratégico para o município de Curitiba é contemplado na revisão do Plano Diretor, onde é destacado que plano é $p$ instrumento estratégico da política de desenvolvimento urbano, sendo composto de planos estratégicos com temáticas setoriais, com prazos e metas estabelecidos.

Os planos estratégicos também possuem a característica de ser um dos instrumentos de efetivação do Sistema Municipal de Planejamento, que articula as políticas públicas com os diversos interesses da sociedade e promove instrumentos para a gestão e o monitoramento do desenvolvimento urbano.

Em 2016, foi iniciado o projeto Curitiba 2035, em parceria com diversos setores (público, privado, universidades, sociedade civil organizada) para o desenvolvimento de um plano de ação de longo prazo para a cidade, contemplando os temas: Governança; Cidade em Rede; Cidade do Conhecimento; Transporte e Mobilidade; Meio Ambiente e Biodiversidade; Saúde e Bem-estar e Coexistência em uma Cidade Global. Para articular a participação dos atores foram constituídos os seguintes grupos de participação: Comitê Executivo, Comitê Gestor, Painel de Atores Estratégicos, Painéis de Especialistas e Consultas Públicas.

A fase inicial, iniciada em 2016 e com duração prevista de dois anos, contempla o diagnóstico dos temas abordados, definição dos atores-chave para a construção do plano e definição dos métodos de interação, participação e produção de conteúdos. Como ferramenta auxiliar da fase de diagnostico, está sendo produzido um estudo socioeconômico da cidade e

Perspectivas em Gestão \& Conhecimento, João Pessoa, v. 9, n. 1, p. 62-81, jan./abr. 2019. 
um mapeamento de investimentos para verificar as condições do crescimento econômico e direcionar o desenvolvimento da cidade.

No tocante ao desenvolvimento econômico, as discussões terão como base o documento Cidades Inovadoras Curitiba 2030, coordenada pelo sistema SESI/SENAI com participação da prefeitura de Curitiba, sociedade civil organizada, universidades e empresas. 0 documento partia da premissa que a tendência de futuro era o estilo de vida digital com a incorporação de novas tecnologias no cotidiano das pessoas, o trabalho mais flexível ancorado em suportes tecnológicos, e um diálogo mais aberto com os governos a partir de projetos de cidade digital. Outro aspecto apontado como tendência futura foi o de cidades em rede, possibilitando a disseminação e o compartilhamento de informações entre governos, sociedade, universidades e empresas por meio das vias digitais estruturadas em rede. $\mathrm{E}$, por ultimo, a economia baseada no conhecimento e em práticas de inovação tecnológica.

Também foram definidos vetores de transformação para a cidade, diretrizes estratégicas para a realização dos objetivos de futuro da cidade: transparência da gestão pública a partir do uso de novas tecnologias de informação, cidadãos e empresas capacitados e conectados em rede global, a potencialização da economia de conhecimento e de inovação, definindo uma nova matriz econômica para o município ancorado em alta tecnologia.

\subsection{Análise do modelo da Cidade Digital do município de Curitiba}

O Plano Plurianual da prefeitura de Curitiba destaca a necessidade da adoção do modelo de cidade digital como ferramenta de suporte para o desenvolvimento da nova economia do município. Esta adoção se dará por meio da constituição de uma infraestrutura tecnológica baseada em meios digitais de alta capacidade de transmissão de dados e que tenha segurança e qualidade. Esta é a forma de desenvolver os talentos da cidade, atrair novos profissionais e fomentar o empreendedorismo da cidade de forma equilibrada e sustentável.

Em 2012, Curitiba se destacou em pesquisa elaborado pelo Centro de Pesquisa e Desenvolvimento em Telecomunicações (CPqD) em parceria com a Momento Editorial, ficando em primeiro lugar ano Índice Brasil de Cidades Digitais. O critério da pesquisa classifica as cidades de acordo com o grau de acesso à internet e nível dos serviços digitais fornecidos a seus habitantes.

Em 2016, o ranking Connected Smart Cities colocou Curitiba em terceiro lugar na classificação das cidades inteligentes. O Ranking Connected Smart Cities tem o objetivo de mapear as cidades com maior potencial de desenvolvimento do Brasil.

Segundo informações do Instituto Cidades Inteligentes (antigo Instituto Curitiba de Informática) que operacionaliza os serviços de tecnologia e informação da prefeitura de Curitiba, há o atendimento de nove mil atendimentos via service desk por mês, mais de 200 sistemas em operação, gestão de 37 mil contas de e-mail, 2500 redes de dados, $1150 \mathrm{Km}$ de fibra óptica, 71 TB de dados armazenados, 5 mil atendimentos via central 156, 140 locais com internet wireless gratuita. Além destes dados destaca-se ainda o sistema de gestão educacional de 300 escolas e 130 mil alunos, 180 mil lances pelo sistema de compras eletrônicas, 15 mil atendimentos na saúde e 14 mil exames laboratoriais por dia.

O portal da prefeitura dispõe de 700 serviços e informações ao cidadão, incluindo serviços para o cidadão (envolvendo questões de alvará, IPTU, horário e itinerário de ônibus, entre outros), serviços para empresas (ISS, certidão negativa, dívida ativa, etc), serviços para os servidores (webmail, RH 24 horas e os sistemas corporativos e departamentais), informações para turistas, de transparência e agenda de eventos e atividades da cidade.

No plano plurianual 2018-2021 prevê um projeto de inovação de modernização tecnologia para as secretarias, procurando desenvolver projetos de documento eletrônico para agilizar os processos de compra, administrativos e jurídicos da prefeitura, contemplando ações

Perspectivas em Gestão \& Conhecimento, João Pessoa, v. 9, n. 1, p. 62-81, jan./abr. 2019. 
de georreferenciamento, Governança de TIC, Data Center e Conectividade. Ainda em relação aos processos internos o plano prevê a adoção de um aplicativo RH 24 horas e adoção do sistema eSocial.

O plano também otimiza a participação e interação do cidadão com o uso da tecnologia por meio do projeto de Democracia Digital, disponibilizando espaços virtuais de relacionamento e uma maior interação com a sociedade por meio das redes sociais.

Em relação ao desenvolvimento urbano, o plano apresenta o sistema eletrônico de fiscalização urbana, o sistema METROGEO de integração metropolitana de banco de dados.

A mobilidade urbana também foi contemplada com o plano de implantação de Wi-Fi em terminais, a expansão de funcionalidades do aplicativo ITBUS de informações do transporte público e a implantação de novo Sistema de Bilhetagem Eletrônica com reconhecimento facial. O plano plurianual apresenta estes projetos como uma política de consolidação de Curitiba como uma Smart City.

\section{ANÁLISE DA RELAÇÃO DA ECONOMIA DA INOVAÇÃO E DO MODELO DE CIDADE DIGITAL ESTRATÉGICA NO MUNICÍPIO DE CURITIBA}

Como Curitiba possui estratégias municipais, informações e serviços públicos eletrônicos para os cidadãos, ela pode ser considerada uma cidade digital estratégica.

Assim, segundo a Secretaria Municipal de Finanças do município de Curitiba, 33,1\% dos estabelecimentos de serviço de tecnologia da informação e $38,6 \%$ das atividades da prestação de serviço de tecnologia são concentradas na região central do município, onde estão localizados, o anel logístico e o setor central Rebouças. Os incentivos fiscais adotados para região colaboraram para o aumento dos estabelecimentos de tecnologia da informação na região central de Curitiba.

As informações do Ministério do Trabalho e Emprego destacam o maior aumento nas ocupações tecnológicas ligadas à tecnologia da informação, devido ao aumento de vagas nas faculdades ligadas ao setor de formação rápida (dois anos). Os cursos tecnológicos apresentam uma formação rápida, com a característica de atender mais rapidamente às demandas do mercado de tecnologia com uma atuação mais generalista. As demais ocupações tendem a ter uma formação mais longa e complexa (prazo de quatro anos), com demandas mais específicas como questões ligadas à segurança da informação, gerência de redes, administração de sistemas, suporte e desenvolvimento de sistemas.

Tabela 1 - Evolução das ocupações ligadas ao setor de tecnologia em Curitiba: 2010 a 2015

\begin{tabular}{l|l|l|l}
\hline Ocupações & $\mathbf{2 0 1 0}$ & $\mathbf{2 0 1 5}$ & VARIAÇÃO \\
\hline Tecnólogo em gestão da tecnologia da informação & 93 & 975 & $\mathbf{9 4 8 , 3 9 \%}$ \\
\hline Administrador em segurança da informação & 93 & $\mathbf{4 2 8}$ & $\mathbf{3 6 0 , 2 2 \%}$ \\
\hline Gerente de rede & 2.017 & 5.317 & $\mathbf{1 6 3 , 6 1 \%}$ \\
\hline Gerente de projetos de tecnologia da informação & 5.361 & 11.449 & $\mathbf{1 1 3 , 5 6 \%}$ \\
\hline Administrador de sistemas operacionais & 7.672 & 13.380 & $\mathbf{7 4 , 4 0 \%}$ \\
\hline Gerente de suporte técnico de tecnologia da informação & 4.203 & 7.059 & $\mathbf{6 7 , 9 5 \%}$ \\
\hline Diretor de serviços de informática & 1.907 & 3.140 & $\mathbf{6 4 , 6 6 \%}$ \\
\hline Gerente de produção de tecnologia da informação & 2.764 & 3.658 & $\mathbf{3 2 , 3 4 \%}$ \\
\hline Analista de informações & 5.883 & $\mathbf{7 . 5 6 6}$ & $\mathbf{2 8 , 6 1 \%}$ \\
\hline Administrador de banco de dados & 2.335 & $\mathbf{2 . 8 0 6}$ & $\mathbf{2 0 , 1 7 \%}$ \\
\hline
\end{tabular}

Perspectivas em Gestão \& Conhecimento, João Pessoa, v. 9, n. 1, p. 62-81, jan./abr. 2019. 


\begin{tabular}{l|l|l|l}
\hline Gerente de desenvolvimento de sistemas & 8.060 & 9.392 & $\mathbf{1 6 , 5 3 \%}$ \\
\hline Administrador de redes & 6.421 & 6.461 & $\mathbf{0 , 6 2 \%}$ \\
\hline Gerente de segurança de tecnologia da informação & 756 & 716 & $\mathbf{- 5 , 2 9 \%}$ \\
\hline TOTAL & $\mathbf{4 7 . 5 6 5}$ & $\mathbf{7 2 . 3 4 7}$ & $\mathbf{5 2 , 1 0 \%}$ \\
\hline
\end{tabular}

Fonte: MTE/RAIS

O planejamento plurianual de Curitiba demonstra uma política pública de desenvolvimento econômico alicerçada no programa Curitiba Criativa, com foco em atividades de tecnologia, de sustentabilidade e da economia verde. No entanto, percebe-se que a política constituída no plano plurianual não está alinhada com os objetivos da política de desenvolvimento da economia informacional, nem com a implantação do parque tecnológico. Embora se perceba um aumento da atividade na economia da cidade, a expansão tem uma forte relação com a existência de instituição de ensino e pesquisa e da concentração de empresas do setor, cabendo um papel reduzido da prefeitura no processo de atração de investimentos.

O município de Curitiba tem desenvolvido um modelo de cidade digital como ferramenta de suporte para o desenvolvimento da economia informacional, disponibilizando 700 serviços e informações para a população por meio do portal da prefeitura. Dispõe ainda de serviços para os servidores como acesso ao sistema de RH, webmail e demais sistemas internos. A prefeitura disponibiliza ainda a infraestrutura lógica para o atendimento das necessidades de tráfego e armazenamento de dados e a gestão de diversos serviços como educação e saúde, entre outros.

Desta forma, percebe-se que o modelo de desenvolvimento de Curitiba está ancorado no incentivo à nova economia informacional e estruturado no Parque Tecnológico. O modelo aplicado em Curitiba nos últimos anos incentiva a economia criativa, mas estabelece dois papéis distintos: a prefeitura é responsável pela infraestrutura lógica de armazenamento e tráfego de dados e a atração de empresas é organizada pelo mercado, através das instituições de ensino e pesquisa ou organizações empresariais.

Destaca-se assim a evolução do papel da prefeitura, primeiro como responsável pela delimitação da área do parque tecnológico e das políticas de incentivo, além de ser o criador das estruturas físicas como incubadoras e prédios para as atividades. Num segundo momento, com a estrutura definida e organizada, a prefeitura fica responsável pela implantação e expansão da estrutura lógica para o atendimento das necessidades tecnológicas dos investimentos na cidade.

\section{CONCLUSÃO}

As cidades, como sistemas complexos, demandam gestão e planejamento municipal cada vez mais completo, contemplando não somente as questões territoriais e de organização do espaço, mas também as questões ligadas aos aspectos sociais e econômicas, ampliando o acesso à cidade e as condições para a convivência no espaço urbano. Neste contexto, o desenvolvimento de novas estruturas faz parte do escopo dos gestores municípios e a implantação dos ecossistemas de inovação articula e aproxima a economia urbana das novas dinâmicas globais com base na produção do conhecimento. Da mesma forma, a economia da inovação está estreitamente relacionada com os conceitos de cidade digital e de estratégias para a cidade e, desta forma, aproximando-se do conceito de cidade digital estratégica.

Como o objetivo foi de compreender como a economia da inovação pode ser desenvolvida a partir da adoção de um modelo de uma cidade digital estratégica, o estudo de

Perspectivas em Gestão \& Conhecimento, João Pessoa, v. 9, n. 1, p. 62-81, jan./abr. 2019. 
caso apresentado demonstrou que o desenvolvimento da economia baseada em atividades ligadas à tecnologia da informação depende de um conceito de cidade digital desenvolvido pelo município, implantando a infraestrutura necessária para armazenamento e tráfego de dados e o estabelecimento de serviços digitais como pré-requisito para a atração de empresas e que permita a expansão da economia do conhecimento. Destaca-se ainda que para que o projeto de cidade digital seja estratégico, faz-se necessário a existência de um planejamento estratégico municipal, orientando ações para uma visão de longo prazo.

No tocante ao caso apresentado no município de Curitiba, implementou-se um modelo de cidade digital baseado no fornecimento de uma infraestrutura para a adoção de um projeto de smart city, bem como na oferta de serviços públicos disponibilizados de forma digital para a população. Essa infraestrutura, uma vez implantada, também se torna importante para o estabelecimento de atividades ligadas à tecnologia da informação e comunicação, fazendo com que estes investimentos contribuam para a indução da economia da inovação.

O artigo demonstrou que existe um programa de incentivo para a instalação de empresas nas áreas delimitadas amparado por um direcionamento das políticas públicas contidas no Plano Plurianual. Como resultado deste processo, percebe-se que estas políticas refletem na distribuição das ocupações ligadas à indústria criativa ligada à alta tecnologia, demonstrando uma expansão das ocupações deste setor, fortalecendo o processo de desenvolvimento econômico ancorado na indústria na alta tecnologia.

Para o incentivo desta nova economia, a prefeitura de Curitiba implantou um sistema local para indução à inovação, contemplando a Lei de Inovação, que determina e normatiza toda a política, formas de fomento, organização do ecossistema, entre outras providências. Estabelece também um Fundo Municipal de Inovação para investimentos neste setor e o Conselho Municipal de Inovação como forma de fomentar a participação da sociedade a interação com o poder local na discussão e deliberação sobre políticas de inovação.

A importância do tema é justificada pelas contribuições que traz para a economia urbana, para a academia e para os gestores municipais. $O$ artigo contribui para o estudo do desenvolvimento econômico dos espaços urbanos, pois estabelece critérios e pré-requisitos para atender as necessidades do modelo de economia baseada nas tecnologias de informação, sendo relevante também para a área de desenvolvimento econômico, gestão de cidades e economia urbana. Também colabora para o estudo das cidades digitais, pois relaciona o conceito com as questões de economia urbana e a evolução das atividades econômicas. Para a academia, o artigo contribui para ampliar a discussão e o debate sobre a configuração e as funções dos modelos de cidade digital. Para os gestores municipais, o artigo contribui com a oportunidade de uma melhor compreensão da definição do modelo de cidade digital estratégica e do alinhamento deste com o planejamento do desenvolvimento econômico das cidades.

A pesquisa traz contribuições para a academia, para a prefeitura e para os estudos sobre cidade digital estratégica. Para a academia, o artigo permite ampliar o debate da relação entre cidade digital estratégica e o desenvolvimento econômico, destacando as análises apresentadas neste trabalho como fonte de motivação para estudos posteriores sobre os temas apresentados. Para as prefeituras, o trabalho permite a identificação de fatores que contribuem para adequar os projetos de cidade digital à política de desenvolvimento econômico municipal, permitindo uma compreensão mais abrangente dos temas propostos. 0 trabalho contribui para o Grupo de Pesquisas em Cidade Digital Estratégica permitindo a expansão dos estudos acadêmicos sobre o tema, ampliando as possibilidades para futuras pesquisas que envolvam o tema da Cidade Digital Estratégica e da Economia da Inovação. Por fim, o trabalho é importante por apresentar uma relação entre tecnologia e da sociedade, buscando apresentar a Cidade Digital Estratégica como forma de incentivar a Economia da Inovação. $\mathrm{O}$ artigo também se destaca por apresentar o tema da Cidade Digital com uma

Perspectivas em Gestão \& Conhecimento, João Pessoa, v. 9, n. 1, p. 62-81, jan./abr. 2019. 
abordagem diferenciada, não focando apenas no aspecto das aplicações da Tecnologia da Informação, mas também da utilização da tecnologia como instrumento de desenvolvimento econômico e de produção do conhecimento.

Algumas limitações da pesquisa não comprometem o seu objetivo e a conclusão do trabalho. Quanto ao método, foi utilizada a abordagem qualitativa de análise, podendo uma análise quantitativa complementar os resultados apresentados. O estudo de caso foi único, podendo ter uma aplicação em múltiplos casos que apresentem resultados comparativos relevantes. Também podem ser ampliadas as variáveis estudadas para expandir os resultados alcançados, trazendo novas contribuições e conclusões para o tema. Finalizando, observou-se que a discussão do conceito de cidade digital é relevante, pois o planejamento para implantação da economia da inovação faz parte das funções municipais e são determinantes na estruturação econômica das cidades.

Como conclusão final, compreende-se que o planejamento estratégico municipal é fundamental para o estabelecimento de uma cidade digital estratégica e, uma vez que este conceito é adotado definem-se objetivos para a gestão municipal que orientam a dinâmica social e econômica dos municípios. No âmbito econômico, a implantação de ecossistemas de inovação articula o desenvolvimento econômico municipal de uma forma estratégica com impactos territoriais e sociais. Compreende-se que como ecossistemas de inovação são instrumentos estratégicos para o desenvolvimento urbano, é fundamental a existência de um plano estratégico para orientar a organização territorial, social e econômica do município sendo que, a não existência destas condições, pode comprometer o desenvolvimento econômico. Compreende-se, por fim, a necessidade do poder local articular um sistema de inovação que contemple uma normativa legal, um espaço de articulação e discussão com a sociedade e a destinação de recursos para investimentos, permitindo assim a indução da economia da inovação no contexto urbano articulado com a ideia de uma cidade digital estratégica.

\section{AGRADECIMENTOS}

Ao apoio do Conselho Nacional de Desenvolvimento Científico e Tecnológico (CNPq), Brasil.

\section{REFERÊNCIAS}

BESSELAAR PVD, BECKERS D. Demographics and sociographics of the digital city. Disponível em: http://portal.acm.org/citation.cfm?id=701393. Acesso em: 2 jan. 2019.

BRASIL. Lei no 10.257, de 10 de julho de 2001: regulamenta os arts. 182 e 183 da Constituição Federal, estabelece diretrizes gerais da política urbana e dá outras providências.

BRASIL. Constituição da República Federativa do Brasil. Diário Oficial, 1988.

CALIFORNIA INSTITUTE FOR SMART COMMUNITIES, 2001, "Ten Steps to Becoming a Smart Community", disponível em: http://www.smartcommunities.org/library 10steps.htm. Acesso em: 20 nov. 2016.

CALMANOVICl, Carlos E. A inovação, a competitividade e a projeção mundial das empresas brasileiras. Revista USP, v. 89, p. 190, 2011. 
CANO, W.; SILVA, A.L.G. (2010). Política industrial do governo Lula. Campinas: IE/UNICAMP, (Texto para discussão, 181).

CASTELLS, Manuel. A Era da Informação: economia, sociedade e cultura. São Paulo: Paz e Terra. 2010.

CHESBROUGH, H. Modelos de negócios abertos: como prosperar no novo cenário da inovação. Porto Alegre: Bookman. 2012.

CIDADES - Ministério das Cidades. Plano diretor participativo: guia para a elaboração pelos municípios e cidadãos, 2004.

CIDADES - Ministério das Cidades. Programas Urbanos. Disponível em: http://www.cidades.gov.br. Acesso em: 22 de outubro de 2016.

DRUCKER, P. The Age of discontinuities. London: Transaction Publications, 1969.

ETZKOWITZ, Henry. Hélice tríplice: Universidade - Indústria - Governo, Inovação em Movimento. Porto Alegre: EdiPUCRS, 2009.

FEITOSA, C. O. A importância da inovação para o desenvolvimento econômico local. Economia Política do Desenvolvimento, v. 4, p. 1-152, 2011.

FERNANDES, Antônio S. A.; MORAES, Douglas B.; NASCIMENTO, Alex M. As Reformas Administrativas nos Estados Brasileiros: O caso da Reforma Administrativa do Estado do Piauí. Cadernos de Gestão Pública, v. 20, p. 194-213, 2015.

FONSECA, J. J. S. Metodologia da pesquisa científica. Fortaleza: UEC, 2002.

FREITAS, Leana O. Políticas públicas, descentralização e participação popular. Revista Katalysis, v. 18, p. 113-122, 2015.

GALLON, A. V.; REINA, D. R. M.; ENSSLIN, S. R. O Impacto do Financiamento da Inovação Promovido pelo Programa Juro Zero da FINEP no Desempenho Econômico-financeiro das MPEls Catarinenses. In: ENCONTRO NACIONAL DE PESQUISA EM ADMINISTRAÇÃO, 34., 2010, Rio de Janeiro. Anais [...]. Rio de Janeiro: ANPAD, 2010.

GERIGK, W.; CLEMENTE, A.; TAFFAREL, M. O impacto da lei de responsabilidade fiscal sobre a gestão financeira municipal: um estudo com os municípios do Paraná. Revista Eletrônica de Ciência Administrativa, Campo Largo, v. 10, n. 1, p. 64-83, maio/2011. Disponível em: http://revistas.facecla.com.br/index.php/recadm. Acesso em: 10 jan. 2019.

GIBBONS, M. et al. New production of knowledge. London: Sage, 1994.

GIUGLIANI, E; SANTOS, N.; SELIG, P. Modelo de Governança para Parques Científicos e Tecnológicos no Brasil. ANPROTEC/SEBRAE, 2012.

IBGE. Pesquisa de Inovação Tecnológica 2014. Rio de Janeiro: Instituto Brasileiro de Geografia e 
http://www.pintec.ibge.gov.br/downloads/PUBLICACAO/PUBLICA\%C3\%87\%C3\%830\%20PINTE C\%202014.pdf. Acesso em: 31 dez. 2018.

LEMOS, André. De que forma as Novas tecnologias - como a computação em Nuvem, o Big Data e a internet das coisas - podem melhorar a condição de vida nos espaços urbanos? GVexecutivo, v. 12, n. 2, jul./dez., 2013 Disponível em: http://bibliotecadigital.fgv.br/ojs/index.php/gvexecutivo/article/viewFile/20720/19454.

Acesso em: 20 dez. 2018.

LEONELLI, F. C. V. A inovação tecnológica na sociedade do conhecimento e o papel social da Embrapa. Revista de Estudos Sociais, v. 1, p. 120-133, 2010.

LEVY, Pierre. A Inteligência Coletiva: por uma antropologia do ciberespaço. Ged. São Paulo: Edições Loyola, 2010.

MUSOLESI, A.; HUIBAN, J. P. Innovation and productivity in knowledge intensive business services. Journal of Productivity Analysis, v. 34, n. 1, p. 63-81, 2010.

NAMBISAN, S.; BARON, R. A. Innovation ecosystems: entrepreneurs self-regulatory processes and their implications for new venture success. Entrepreneurship: Theory and Practice, v.37, n.5, p.1071-1097, 2013.

QUADROS, P. R. N. S. As incubadoras de empresas: gênese, desenvolvimento, declínio e perspectivas futuras no contexto político-institucional de inovação tecnológica do Estado da Bahia (1993-2010). 2010. Dissertação (Mestrado em Administração) - Universidade Federal da Bahia, 2010.

REZENDE, D. A. Planejamento de estratégias e informações municipais para cidade digital: guia para projetos em prefeituras e organizações públicas. São Paulo: Atlas, 2012.

REZENDE, D. A. Cidade digital estratégica: conceito e modelo - estratégica digital city: concept anda model. In: INTERNATIONAL CONFERENCE ON INFORMATION SYSTEMS AND TECHNOLOGY MANAGEMENT, 15, 2018, São Paulo. Anais [...]. São Paulo: CONTECSI USP Editora, 2018. v. 1. p. 1-18.

REZENDE, D. A.; CASTOR, B. V. J. Planejamento estratégico municipal: empreendedorismo participativo nas cidades, prefeituras e organizações públicas. 2 ed. Rio de Janeiro: Brasport, 2006.

SCHUMPETER, J. Teoria do desenvolvimento econômico. Abril Cultural, São Paulo, 1982.

SIMÃO, João B.; SUAIDEN, E. J. Cidades digitais em municípios brasileiros de pequeno porte: proposta de um modelo de implantação. Inclusão Social (Impresso), v. 5, p. 99-116, 2012.

STONEMAN, P. Soft innovation: economics, product, aesthetics, and the creative industries. Oxford University Press. 366 p. 2010.

STRACHULSKI, JULIANO. O desenvolvimento econômico local: da perspectiva econômica a perspectiva sociocultural / The local economic development: of the economic perspective the sociocultural perspective. Caderno de Geografia, v. 27, p. 304-319, 2017. 
STRAPAZZON, Carlos L. Convergência tecnológica nas políticas urbanas: pequenas e médias "cidades inteligentes". Revista Jurídica, v. 22, n. 6, p. 89-108, 2011.

VELOSO, João F. A. et al. Gestão municipal no Brasil: um retrato das prefeituras. Brasília: Ipea, 2011.

VIEIRA, Edson T.; SANTOS, Moacir J. Desenvolvimento Econômico Regional - Uma revisão histórica e teórica. Revista Brasileira de Gestão e Desenvolvimento Regional. v. 8, n. 2, 2012.

Artigo recebido em 18/02/2018 e aceito para publicação em 09/02/2019 